\title{
Current Concepts on \\ Management of Chronic Hepatitis B
}

\author{
Teresa Santantonio and Massimo Fasano \\ Additional information is available at the end of the chapter \\ http://dx.doi.org/10.5772/54759
}

\section{Introduction}

An estimated 400 million people are chronically infected with hepatitis B virus (HBV), worldwide, and over 500,000 chronic hepatitis B (CHB) patients die annually because of cirrhosis and hepatocellular carcinoma (HCC) [1,2]. Clinical care for patients with CHB has advanced considerably during the last decades as a result of growing knowledge about the mechanisms of disease, diagnostic procedures and advances in therapeutic options.

Since the introduction of interferon alpha as first antiviral therapy at the end of the 1980s, management of $\mathrm{CHB}$ has dramatically evolved due to the availability of direct antivirals which greatly increased the therapeutic options, thus permitting treatment of patients previously excluded from IFN treatment. In particular, new oral antivirals have been developed and used in clinical practice, leading to a substantial improvement in antiviral efficacy, mainly due to their increased potency and higher barrier to resistance. On the other hand, the expanding molecular and clinical knowledge of HBV infection and evolution of therapy have made the management of $\mathrm{CHB}$ patients much more complex. Therefore, within the recent past, several guidelines have been issued by many organizations and professional expert panels in order to better define diagnostic criteria and improve therapeutic decisions.

This chapter focuses on the current management of chronic hepatitis B patients and reviews up-to-date studies and concepts regarding antiviral treatment.

\section{Pre-therapeutic assessment}

Chronic HBV infection is not necessarily accompanied by progressive liver disease requiring antiviral therapy. Therefore, as a first step, an accurate evaluation of all HBsAg-positive 
carriers is required in order to identify: a) the phase of infection, b) the subjects with chronic liver damage, c) the stage of liver disease, d) the concurrent causes of liver disease, and e) patients requiring treatment.

The natural history of chronic HBV infection can be divided into five, not necessarily sequential, phases (Figure 1). Firstly, the (i) immune-tolerant phase is characterized by high levels of serum HBV DNA, HBeAg positivity, normal ALT levels, and mild or absent liver necroinflammation. In patients who remain in the immune-tolerant phase, disease progression is minimal [3]. After a variable time depending on the age at acquisition of $\mathrm{HBV}$ infection, immune-tolerance to the virus is lost and the immune system mounts an attack on the infected hepatocytes, thus entering into the (ii) immune-reactive phase. This phase is characterized by fluctuating, but progressively decreasing, HBV-DNA levels, elevated ALT and hepatic necroinflammation (HBeAg-positive $\mathrm{CHB}$ ). A prolonged immune-reactive phase with multiple ALT flares may result in progressive liver fibrosis, leading to cirrhosis. An important outcome of the immune-reactive phase is the seroconversion from $\mathrm{HBeAg}$ to anti-HBe, thus marking the transition to the (iii) immune-control phase, characterized by low $(<2000 \mathrm{IU} / \mathrm{ml})$ or undetectable serum HBV DNA, normal ALT levels, and disappearance of liver necroinflammation (inactive carrier state). The estimated annual incidence of spontaneous HBeAg seroconversion is $2 \%-15 \%$, depending on factors such as age, ALT levels, and HBV genotype [2]. In a minority of patients, despite HBe seroconversion, reactivation of HBV replication may occur due to the selection of HBeAg defective HBV mutants. This (iv) reactivation phase is characterized by positivity for anti-HBe antibodies, fluctuating $\mathrm{HBV}$ DNA and ALT levels and a high risk of progression to severe hepatic fibrosis (HBeAg-negative $\mathrm{CHB}$ ). In patients with periodic ALT flares and normalization, HBV-DNA levels can fall below the inactive carrier cut-off $(2000 \mathrm{IU} / \mathrm{ml})$, making differential diagnosis between active CHB and the inactive carrier status problematic. Therefore, to warrant an accurate differential diagnosis, it is mandatory to monitor serum HBV-DNA by sensitive and quantitative polymerase chain reaction (PCR) assays and ALT levels over a period of at least 1 year. A recent study, however, demonstrated that a single-point combined quantification of HBV-DNA $(<2000 \mathrm{IU} / \mathrm{ml})$ and $\mathrm{HBsAg}(<1000 \mathrm{IU} / \mathrm{mL})$ permits to identify inactive HBV genotype D carriers with a very high diagnostic accuracy which is comparable to that of 1-year monthly monitoring [4]. In the (V) "HBsAg-negative phase" after HBsAg loss, low-level HBV replication may persist with detectable HBV DNA in the liver [5]. In patients with "occult" HBV infection the persistence of an efficient HBV immunological control has been demonstrated [6], and it is now well known that immunosuppression may lead to HBV reactivation in these patients.

On the basis of the serological and virological profile, three distinct HBsAg carrier types can be identified, each characterized by a distinct natural course, prognosis, and treatment indications: 1) immune tolerant carrier, 2) inactive carrier, 3) carrier with $\mathrm{CHB}$ (HBeAg-positive and $\mathrm{HBeAg}$-negative $\mathrm{CHB}$ ). In both tolerant and inactive HBV carriers, treatment is not indicated, but an appropriate longitudinal follow-up is crucial. Immunotolerant patients should be subjected to ALT measurements every 3-6 months and should be tested for the presence of HBeAg every 6 months. In the inactive carriers, ALT and HBV DNA levels should be assessed every 3 months during the first year, and then every 6 months [7-9]. Patients with serum HBV DNA <2000 IU/ml and levels of HBsAg less than $1000 \mathrm{IU} / \mathrm{ml}$, may require less frequent monitoring due to a very low probability of disease reactivation [7]. 


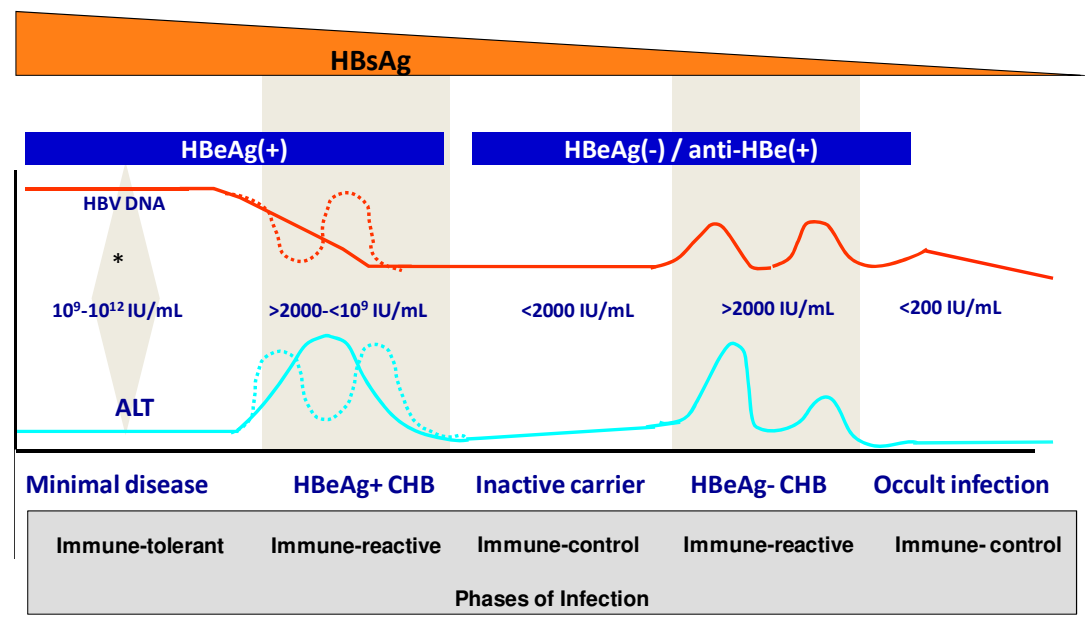

Figure 1. Natural history of chronic HBV infection

In the $\mathrm{HBs} A g$ carriers with $\mathrm{CHB}$, the diagnostic work-up must be continued and the severity of liver disease should be assessed by laboratory tests, and hepatic ultrasound examination. A liver biopsy would be useful for determining the grade of necroinflammation and stage of fibrosis. Prognosis and management of $\mathrm{CHB}$ greatly depend on the stage and progression of liver fibrosis and thus the risk of developing cirrhosis. In addition, liver biopsy may help to clarify diagnosis when ALT and HBV DNA levels are discordant and to exclude other coexistent causes of liver disease (e.g. fatty liver or alcoholic liver disease).

Liver biopsy has traditionally been considered the "gold standard" to measure fibrosis. However, liver biopsy is an invasive procedure which can be painful, and carries a small risk of complications; it is also costly and prone to sampling errors. To provide a reliable estimation of grading and staging of liver disease, liver biopsy specimens should be at least 20-25 mm long and/or containing more than 11 complete portal tracts [10]. Recently, non-invasive methods, including serum markers and transient elastography, are being increasingly utilized to assess liver fibrosis [10]. Transient elastography (FibroScan) is a rapid, noninvasive, and reproducible method for measuring liver stiffness, which correlates with the degree of liver fibrosis. It has demonstrated a high diagnostic accuracy for the detection of cirrhosis, but transient elastography might be inaccurate in discriminating between the different stages of intermediate fibrosis (F1 vs F2), F2 being considered the threshold for initiating antiviral therapy. Moreover, stiffness measurement may be influenced by potential confounding factors such as additional space-occupying tissue abnormalities (e.g. oedema and inflammation, cholestasis).

Lastly, in the diagnostic work-up of $\mathrm{CHB}$, the presence of other possible liver damaging cofactors (co-infections with HDV, HCV and HIV, co-morbidities including alcoholism, autoimmune or metabolic liver disease) which would increase the risk of progression to cirrhosis or HCC should be assessed [11]. 


\section{Treatment indications}

Candidates for treatment are the HBsAg carriers with CHB and, consequently, those with active viral replication, increased ALT levels and evidence of liver disease at liver biopsy or other non-invasive methods.

According to the $2012 \mathrm{HBV}$ guidelines of the European Association for the Study of the Liver (EASL), patients should be considered for treatment when they present HBV DNA levels above $2000 \mathrm{IU} / \mathrm{ml}$, serum ALT levels above the upper limit of normal (ULN) and a liver biopsy showing moderate to severe necroinflammation and/or at least moderate fibrosis using a standardized score system. The comparison between EASL guidelines and American Association for the Study of Liver Diseases (AASLD) guidelines and Asian Pacific Association for the Study of the Liver (APASL) guidelines can be found in Table 1.

However, patients with compensated or decompensated cirrhosis and detectable HBV DNA should be considered for treatment, independent of ALT levels. Moreover, treatment indications should also take into account the patient's age, health status, family history of HCC or cirrhosis and extrahepatic manifestations.

\begin{tabular}{|c|c|c|c|}
\hline Criteria & EASL 2012(Ref.7) & AASLD 2009(Ref.8) & APASL 2008 (Ref.9) \\
\hline \multicolumn{4}{|l|}{$\begin{array}{l}\text { HBV DNA treatment } \\
\text { threshold }\end{array}$} \\
\hline$-\mathrm{HBeAg}(+)(\mathrm{IU} / \mathrm{mL})$ & 2,000 & 20,000 & 20,000 \\
\hline - HBeAg(-) (IU/mL) & 2,000 & $2,000-20,000$ & 2,000 \\
\hline ALT treatment threshold & $>U L N$ & $>2 \times$ ULN & $>2 \times$ ULN \\
\hline Liver Biopsy & $\begin{array}{l}\text { Moderate to severe } \\
\text { necroinflammation } \\
\text { or fibrosis }\end{array}$ & \multicolumn{2}{|c|}{$\begin{array}{c}\text { Not applicable } \\
\text { (Consider in certain groups) }\end{array}$} \\
\hline
\end{tabular}

Table 1. EASL guidelines compared to other international guidelines

\section{Goal of therapy and end-points}

The ultimate goal of CHB therapy is the prevention of cirrhosis, hepatic decompensation and/ or HCC [7-9]. This goal can be achieved if HBV replication can be suppressed in a sustained manner, thus leading to biochemical remission, HBe seroconversion in HBeAg-positive patients, histological improvement and prevention of cirrhosis and its complications. Several studies have demonstrated that undetectable or low levels of HBV DNA are associated with a lower risk to develop cirrhosis [12-14].

Loss of HBsAg from serum with or without seroconversion to anti-HBs is considered the ideal end-point of therapy, as it is associated with remission of chronic hepatitis B activity and an im- 
proved long-term outcome [11]. The loss of HBsAg, however, is infrequently achieved with currently available anti-HBV agents. Hence, a more realistic end-point is the induction of a sustained or maintained virological response. It must be emphasized that a complete eradication of HBV infection is impossible to achieve due to the persistence of the so-called covalentlyclosed-circular DNA (ccDDA), the transcriptionally active HBV mini-cromosome in the nucleus of infected hepatocytes; that is to say, that an HBV infected patient can be "cured" but the $\mathrm{HBV}$ infection cannot be eradicated and continues to persist as an occult infection.

\section{Anti-HBV drugs}

Two different types of drugs have been approved for the treatment of CHB: conventional interferon alpha (IFN) and its pegylated form (Peg-IFN), and 5 nucleoside/nucleotide analogues (NAs) (Figure 2). Currently, IFN has been replaced by Peg-IFN due to the more convenient administration (once weekly). There are two pegylated-IFN formulations: Peg-IFN alpha-2a and Peg-IFN alpha-2b which have shown similar efficacy in clinical trials, but only the former is globally licensed for treatment of CHB, while Peg-IFN alpha- $2 \mathrm{~b}$ has been approved in only a few countries. Among the nucleoside analogues with anti-HBV activity, emtricitabine is not licensed for HBV treatment in most European countries and its combination with tenofovir in one tablet (Truvada) has been licensed only for treatment of human HIV infection.

\section{Chronic Hepatitis B}

\section{Approved drugs}
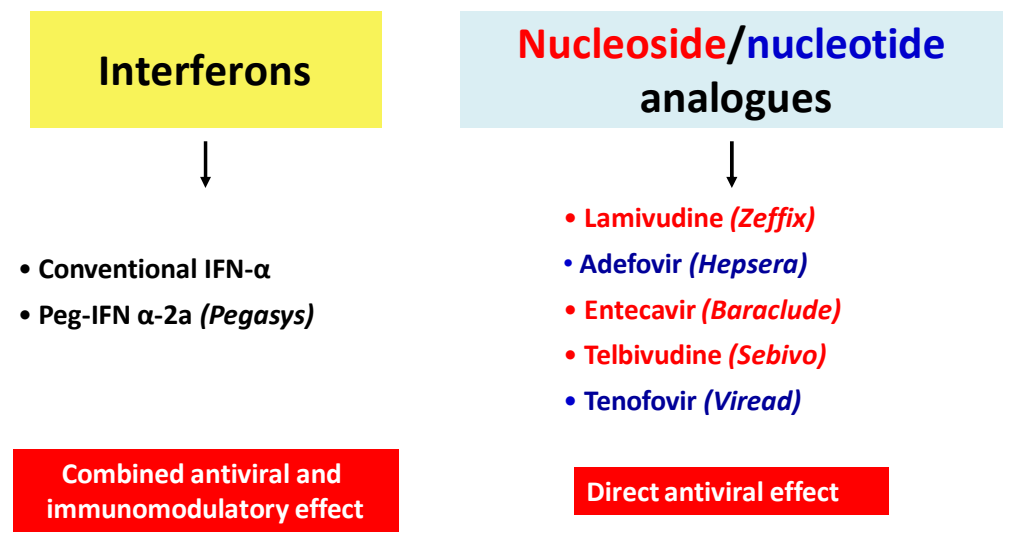

immunomodulatory effect

Direct antiviral effect

Figure 2. Approved drugs for therapy of chronic hepatitis B 


\section{Peg-interferon}

Peg-IFN is a cytochine with a dual antiviral and immunomodulatory activity and is administered by subcutaneous injections. After binding with receptors located on the surface of several different cells, it induces the activation of at least 40 cellular genes, encoding for several antiviral proteins. Peg-IFN suppresses HBV virion budding, HBV entry and synthesis of the nucleocapsid; moreover, this cytochine enhances the interaction between the antigen-presenting cells and CD4, and between CD8 and infected hepatocytes. Therefore, Peg-IFN has the potential for an immune-mediated control of HBV infection, thus providing the opportunity to obtain a sustained virological response after treatment discontinuation, and the possibility of inducing HBsAg loss in patients who achieve and maintain undetectable HBV DNA. IFN-based treatment, however, is often complicated by the occurrence of side effects, such as influenza-like symptoms, fatigue, neutropenia, thrombocytopenia, and depression, which sometimes require dose modification and cause premature cessation of treatment [15]. Moreover, Peg-IFN is contraindicated in patients with decompensated HBV-related cirrhosis or autoimmune disease, in patients with uncontrolled severe depression or psychosis, in patients receiving immunosuppressive therapy or chemotherapy, and in female patients during pregnancy [7].

\section{Nucleoside/nucleotide analogues}

NAs are oral direct antiviral agents which specifically inhibit the viral polymerase/reverse transcriptase, an enzyme with a crucial role in the HBV life cycle. As a result, NAs block the production of new virions and progressively reduce serum HBV DNA to undetectable levels, but they have little or no effect on the cccDNA present in the nucleous of the infected hepatocytes. The persistence of the intrahepatic cccDNA determines the reactivation of HBV replication after stopping NA treatment and therefore justifies the need for a long-term (potentially life-long) therapy for a sustained viral replication control.

After lamivudine (LAM), the first nucleoside analogue approved for the treatment of CHB, another two nucleosides, telbivudine (LdT) and entecavir (ETV), and two nucleotide analogues, adefovir (ADV) and tenofovir (TDF) have become gradually available in recent years. NAs are characterized by a different antiviral potency and drug-resistance pattern. Entecavir and tenofovir are the two most potent analogues with a high barrier to resistance development. Resistance rates in NA-naïve patients treated with monotherapy are shown in Figure 3.

The main advantages and disadvantages of Peg-IFN and NAs in the treatment of CHB are shown in the following Table 2.

\section{Treatment strategies}

There are two different therapeutic strategies for both HBeAg-positive and HBeAg-negative CHB patients: short-term or "curative" treatment and long-term or "suppressive" treatment 
(Figure 4). The first strategy aims to obtain a sustained suppression of viral replication offtreatment by inducing an immune controll status of HBV infection. The immune control status corresponds to the profile of an inactive carrier: normal ALT levels coupled with HBV DNA $<2000 \mathrm{IU} / \mathrm{ml}$ and anti-HBe positivity. This strategy is IFN-based (Peg-IFN administered for 48 weeks); a finite treatment with NA is possible only in HBeAg-positive patients. The second strategy aims to obtain a rapid and long-term maintained viral suppression (HBV DNA $<10-15$ $\mathrm{IU} / \mathrm{ml})$. This strategy is exclusively based on NAs.

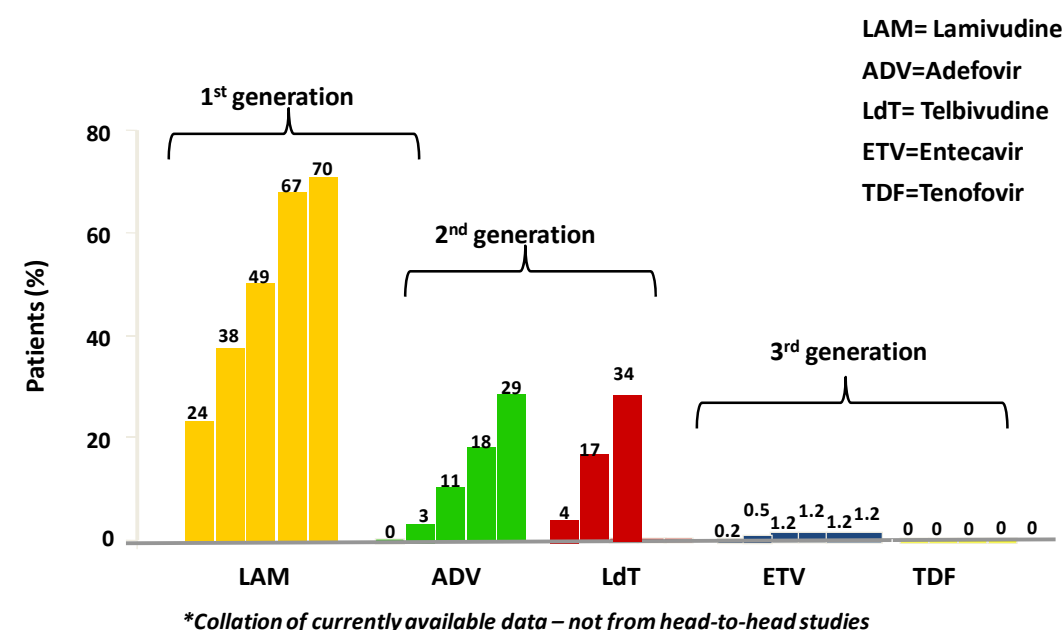

EASL 2012 HBV Guidelines (Ref. 7)

Figure 3. Incidence of Resistance in NA-naïve patients

\begin{tabular}{|c|c|c|}
\hline & Peg-IFN & NAs \\
\hline Advantages & $\begin{array}{l}\text { - Finite duration } \\
\text { - Higher rates of anti-HBe } \\
\text { \& anti-HBs seroconver- } \\
\text { sion with } 12 \text { mos of } \\
\text { therapy } \\
\text { - Absence of resistance }\end{array}$ & $\begin{array}{l}\text { - Potent antiviral effect } \\
\text { - Good tolerance } \\
\text { - Oral administration }\end{array}$ \\
\hline Disadvantages & $\begin{array}{l}\text { - Moderate antiviral effect } \\
\text { - Inferior tolerability } \\
\text { - Risk of adverse events } \\
\text { - Subcutaneous injections }\end{array}$ & $\begin{array}{l}\text { - Indefinite duration } \\
\text { - Risk of resistance } \\
\text { - Unknown long-term safety }\end{array}$ \\
\hline
\end{tabular}

Table 2. Main advantages and disadvantages of Peg-IFN and Nucleos(t)ides analogues (NAs) in chronic hepatitis B 


\section{Short-term "curative" treatment}

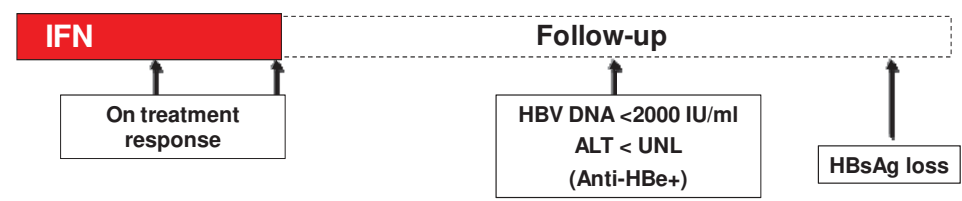

Long-term "suppressive" treatment

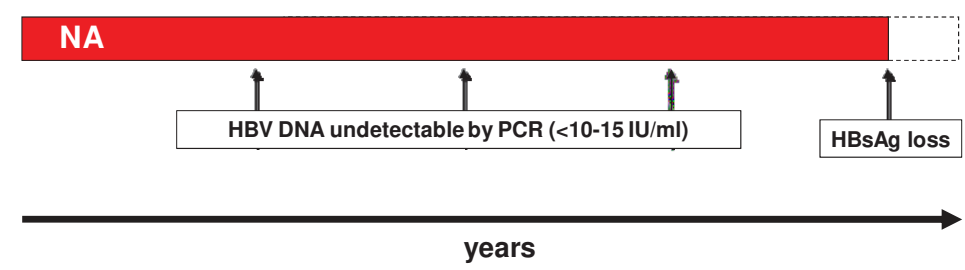

Figure 4. Therapeutic strategies for chronic hepatitis B

\section{First-line monotherapy}

Peg-IFN, entecavir or tenofovir are recommended as first-line monotherapy by all major guidelines in patients with $\mathrm{CHB}$ or compensated cirrhosis [7-9]. The choice of first-line monotherapy should be based on several factors including host, virus and drug related factors (Figure 5). The most favourable candidates for Peg-IFN are those with low HBV DNA levels, high ALT and HBV genotype A or B rather than C or D, and those without advanced disease. Peg-IFN alpha-2a is administered as subcutaneous injections at the dose of $180 \mu \mathrm{g}$ once weekly for 48 weeks.

Entecavir or tenofovir are the only therapeutic options in patients with decompensated liver disease, in patients undergoing immunosuppressive treatment, in patients with controindications or unwilling to receive Peg-IFN. The licensed entecavir dose for patients with decompensated cirrhosis is $1 \mathrm{mg}$ (instead of $0.5 \mathrm{mg}$ for patients with $\mathrm{CHB}$ or compensated liver disease) once daily. Tenofovir is administered orally at dosage of $245 \mathrm{mg} / \mathrm{die}$.

For oral antiviral agents, in HBeAg-positive patients, treatment can be discontinued after a 12 month-consolidation therapy from documented HBeAg seroconversion with undetectable HBV DNA. Close monitoring for relapse is required following therapy discontinuation. In HBeAg-negative patients, long-term treatment is necessary and can be stopped when confirmed HBsAg loss occurs $[7,8]$. 
As Peg-IFN can achieve a sustained off-therapy response in only a minority of cases, and a proportion of patients cannot tolerate or present controindications to IFN or do not wish to be treated with Peg-IFN, long-term treatment with NAs is the most commonly used treatment strategy.

\section{First-line monotherapy}

\section{Choice based on:}

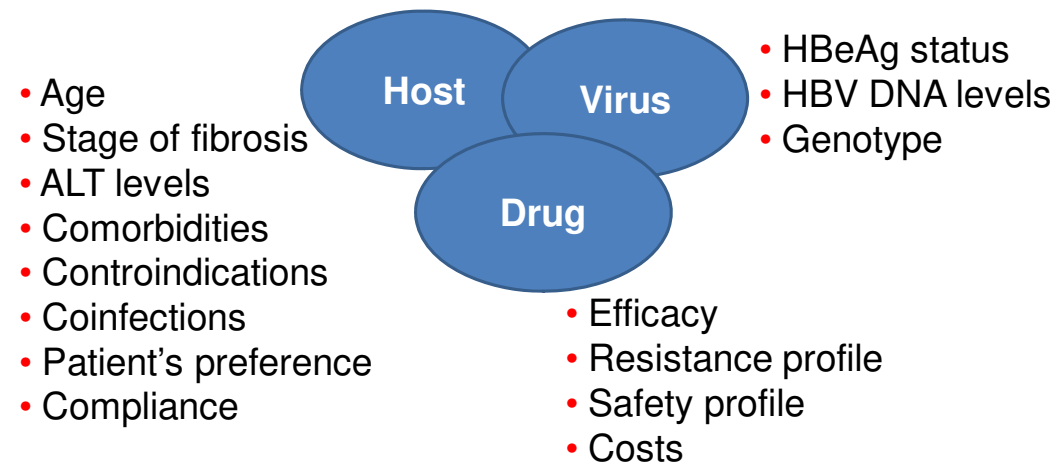

Figure 5. Factors influencing the choice of first-line monotherapy

\section{Virological and non-virological monitoring}

During Peg-IFN therapy, full blood counts and serum ALT levels should be monitored monthly and TSH should be assessed every 3 months. All patients should be monitored for safety throughout the 12 months of treatment. Serum HBV DNA levels should be assessed by real-time PCR at 3, 6, 12 months during treatment and at 6 and 12 months post-treatment. Quantitative determination of serum HBsAg levels should be checked after 3 months of therapy in order to identify patients with a low probability of response in whom IFN therapy discontinuation should be considered [7]. In HBeAg-positive patients, $\mathrm{HBeAg}$ and anti-HBe should be tested every 6 months. Lastly, in all responder patients, HBsAg should be checked at 12-month intervals [7].

In patients treated with NAs, HBV DNA levels should be monitored at month-3 to ascertain virological response, and thereafter, every 3-6 months. In patients treated with ETV or TDF, the frequency of DNA measurements may be decreased once patient compliance and treatment efficacy are confirmed. In HBeAg-positive patients, HBeAg and anti-HBe should be tested every 6 months. HBsAg should be checked at intervals of 12 months in all patients with undetectable HBV DNA by real-time PCR [7]. 
All NAs are cleared by the kidneys, therefore all patients should be tested for serum creatinine levels and estimated creatinine clearance at baseline to identify the need for dose adjustments. As the nephrotoxic potential damage seems to be higher for nucleotide analogues, it is recommended for patients treated with ADV or TDF renal monitoring, including serum phosphate levels every three months during the first year and every 6 months thereafter. In patients at high renal risk or in those who develop clearance creatinine $<60 \mathrm{ml} / \mathrm{min}$ or serum phosphate $<2 \mathrm{mg} / \mathrm{dl}$, a closer renal monitoring is required [7].

\section{IFN-based therapy: Update}

Published data have demonstrated that in patients with HBeAg-positive CHB, Peg-IFN achieves a more than $30 \% \mathrm{HBeAg}$ seroconversion rate after one year of treatment [7]. In a registration trial, Peg-IFN alpha-2a provided a sustained immune control which increased posttherapy; in fact, the HBeAg seroconversion rate continued to increase from $27 \%$ at the end of treatment to $32 \%$ during the six months after discontinuing treatment, and to $42 \%$ after 1 year post-treatment $[16,17]$. Moreover, the seroconversion remained stable over time in $>80 \%$ of PegIFN alpha-2b treated patients achieving this end-point at the end of therapy [18]. Peg-IFN also determined HBsAg seroconversion in up to $30 \%$ of patients with a long-term follow-up [19].

In patients with $\mathrm{HBeAg}$-negative $\mathrm{CHB}$, Peg-IFN alpha-2a demonstrated a sustained immune control (HBV DNA <2000 IU/ml) in 31\% of patients after 1-year post-treatment. Among these, $88 \%$ maintained this response up to 5 -year follow-up, and remarkably $28 \%$ achieved $\mathrm{HBsAg}$ clearance after 5-years post-treatment [20].

Thus, Peg-IFN treatment remains an attractive therapeutic option, since it provides higher rates of off-therapy immune control, including HBsAg clearance, when compared with NAs. However, IFN is effective in only a minority of patients (20-30\%), has a poor tolerability and significant costs. Therefore, the improvement of Peg-IFN efficacy is a major challenge. Several attempts have been made to optimize the cost-effectiveness of IFN-based therapy, including combination therapy, duration of therapy, pre-treatment predictors of response, and on-treatment predictors of response. De novo combination therapy with NAs, did not improve sustained response in either HBeAg-positive or HBeAg-negative patients [16,21-23]. Regarding duration of therapy, the NEPTUNE study conducted in patients with HBeAg-positive $\mathrm{CHB}$ reported that dose and duration are important because the highest sustained response was obtained with $180 \mu \mathrm{g}$ and 48 weeks compared to $90 \mu \mathrm{g}$ and 24 weeks [24]. A recent study has demonstrated that extended treatment with Peg-IFN alpha-2a to 96 weeks was well-tolerated and improved the rates of sustained virological response ( $29 \%$ vs $12 \%$ ) in HBeAg-negative genotype D patients when compared to the current standard of care of 48 weeks. In addition, after 1-year post-treatment, HBsAg clearance (6\%) was observed only in the extended therapy group [25].

There have been many attempts to identify pretreatment predictors of response, resulting in the identification of high ALT levels, low HBV DNA, and virus genotype as significant predictors [7-9]. When combining data from the two largest clinical trials regarding HBeAgpositive $\mathrm{CHB}$ patients $[16,26]$, Buster et al. found that the best candidates for a sustained 
response to Peg-IFN were genotype A patients with high levels of ALT (ALT $\geq 2 x U L N$ ) or low levels of HBV DNA ( $<9 \log _{10}$ copies/ml), and genotypes B and C patients who have both high levels of ALT and low HBV DNA. Genotype D patients have a low chance of sustained response [19]. However, these factors cannot accurately predict response at the individual level; furthermore, ALT and HBV DNA levels are time-dependent and thus their use in clinical practice is difficult.

To obtain additional insight into the individual patient's probability of achieving response to Peg-IFN, the presence of precore and basal core promoter mutants before treatment has been correlated to the serological and virological response in HBeAg-positive CHB patients [27]. Data from this study demonstrated that the presence of a wild-type virus at baseline was an independent predictor of response to Peg-IFN and can assist in improving patient selection for this treatment option [27]. Lastly, the role of IL28B polymorphisms, clearly indicated as a baseline host factor predictor of response in patients with chronic hepatitis $\mathrm{C}$, has been also investigated in $\mathrm{CHB}$ patients. Studies in $\mathrm{HBeAg}$-positive patients provided conflicting results, while, in the only study carried out in HBeAg-negative genotype D patients, the rs12979860 genotype in the IL28B locus independently predicted both virological and serological responses [28-31]. Therefore, further studies are necessary to define the role of IL28B polymorphisms as a baseline factor to improve pretreatment patient selection.

A promising approach to improve the cost-effectiveness of Peg-IFN therapy is a responseguided treatment, based on HBsAg kinetics which permit early identification of either responders, for whom continuation of treatment to week 48 could be beneficial, or nonresponders who should discontinue IFN treatment.

Two stopping rules at week 12 have been proposed for HBeAg-positive patients: 1) no HBsAg decline, 2) HBsAg levels $>20000 \mathrm{IU} / \mathrm{ml}[24,32,33]$. The negative predictive value (NPV) for a sustained response ranged from $82 \%$ to $100 \%$, depending on prevalence of HBV genotypes in the various studies. In HBeAg-negative genotype D patients, no HBsAg decline and $<2$ log copies/ml HBV DNA decline at week 12 has been proposed as a stopping rule and independently validated with a 100\% NPV [34,35]. Overall, therapy with Peg-IFN could be discontinued at week 12 in the $20 \%$ of primary non-responders, who are therefore candidates for suppressive therapy with NAs.

\section{NA-based therapy: Update}

Entecavir and tenofovir are the third-generation NAs recommended as first line therapy for CHB NA-naïve patients by all international guidelines. In registration trials, both antivirals demonstrated a long-lasting efficacy (viral suppression in more than $95 \%$ of patients over 5 years) associated with prevention of developing cirrhosis and to a greater extent, with fibrosis regression [36-40]. Moreover, these studies reported a minimal risk of drug resistance $(1.2 \%$ with ETV after six years and $0 \%$ with TDF after 5 years) and a favourable safety profile [39-43]. However, as registration trials are conducted under standardized conditions in well-selected and compliant patients, long-term efficacy and safety of ETV and TDF remain to be confirmed in real- 
life patients who generally have a more complex clinical profile as they are usually older with a higher prevalence of cirrhosis and comorbidities treated with several concomitant medications.

\section{Entecavir in real-life practice}

Currently, 2,736 CHB naïve patients have been treated with ETV monotherapy in six real-life studies and 4-year efficacy and safety data are available for two of these. In a multicenter Italian study, 418 consecutive NA-naïve patients initiating treatment with ETV $0.5 \mathrm{mg} / \mathrm{die}$ were enrolled. In this cohort, at baseline patients were older (median age 58 years), were predominately infected with HBV genotype D (90\%), presented a diagnosis of cirrhosis in $49 \%$ and concomitant disease in $56 \%$. Viral suppression was achieved in $100 \%$ of patients over 48 months of therapy, independent of HBeAg status. Only one patient with a partial virological response at week 48 developed resistance at year 3 of treatment with a cumulative rate of $0.2 \%$. In HBeAg-positive patients, the 4-year cumulative probability of HBeAg seroconversion and HBsAg loss were $56 \%$ and $21 \%$, respectively. However, despite persistent suppression of viral replication, HCC developed in cirrhotic patients at $2.5 \%$ yearly rates, making continuous surveillance for liver cancer mandatory [44].

A cohort from Hong Kong included 222 NA-naïve patients who demonstrated a 96\% 4-year cumulative rate of virological response [45]. Only one patient developed resistance, corresponding to a $0.6 \%$ cumulative resistance rate up to year- 4 .

The safety profile of ETV in real-life studies has been excellent, as there have been no reports of drug-related adverse reactions, discontinuation, or renal toxicity [44-46].

In the VIRGIL multicenter study including 243 consecutive NA-naïve patients receiving ETV monotherapy, the cumulative probability of achieving a virological response at week 144 was 90\% in HBeAg-positive patients and $99 \%$ in HBeAg-negative patients [47]. In this cohort, 81\% of patients with partial virological response at 48 weeks reached a virological response during prolonged ETV monotherapy and no patient developed ETV resistance. When stratifying patients according to their viral load at week $48,95 \%$ of patients with $\mathrm{HBV}$ DNA $<1000 \mathrm{IU} / \mathrm{ml}$ and $57 \%$ of patients with $\mathrm{HBV}$ DNA $>1000 \mathrm{IU} / \mathrm{ml}$ achieved a virological response without treatment adaptation during the prolonged treatment period beyond week 48 . Therefore, the authors concluded that no treatment adaptation is needed in the majority of NA-naïve patients treated with ETV and obtaining partial virological response, particularly in those with HBV DNA $<1000 \mathrm{IU} / \mathrm{mL}$ at week 48. In addition, data from the Virgil cohort demonstrated that in cirrhotic patients, virological response to ETV is associated with a lower probability of developing a clinical event and disease progression [48].

\section{Tenofovir in real-life practice}

A total of 1,203 CHB patients, including both NA-naïve and experienced, were treated with TDF monotherapy in real-life. In the multicenter European cohort study, 302 consecutive NA- 
naïve patients receiving tenofovir $(245 \mathrm{mg} / \mathrm{die})$ were retrospectively and prospectively followed for a median period of 28 months. At baseline, median age was 55 years, 35\% of patients had cirrhosis, and concomitant diseases were present in 43\% [49]. By month 36, virological response was reached in $86 \%$ of HBeAg-positive patients and $98 \%$ of $\mathrm{HBeAg}$ negative patients. No patient developed drug resistance and, in HBeAg-positive patients, cumulative probability of $\mathrm{HBeAg}$ seroconversion at 30 month was 33\%. Most partial virological responders at week 48 achieved undetectable HBV DNA during additional treatment. Data from this European cohort confirmed the safety profile of TDF reported in the registration studies. Discontinuation therapy was reported in 9 patients $(3 \%)$ including renal-related adverse events in two. The TDF dose was reduced in ten patients (3\%) because of a decline in the estimated glomerular filtration rate [49].

\section{Antiviral treatment failure}

All patients receiving NA-therapy for $\mathrm{CHB}$ should be closely monitored for virologic response defined as undetectable HBV DNA by a sensitive PCR assay. Failure of antiviral therapy may be due to several reasons and three types of treatment failure can be identified: 1) Primary Non Response; 2) Partial Virologic Response; 3) Virologic Breakthrough [50] (Figure 6).

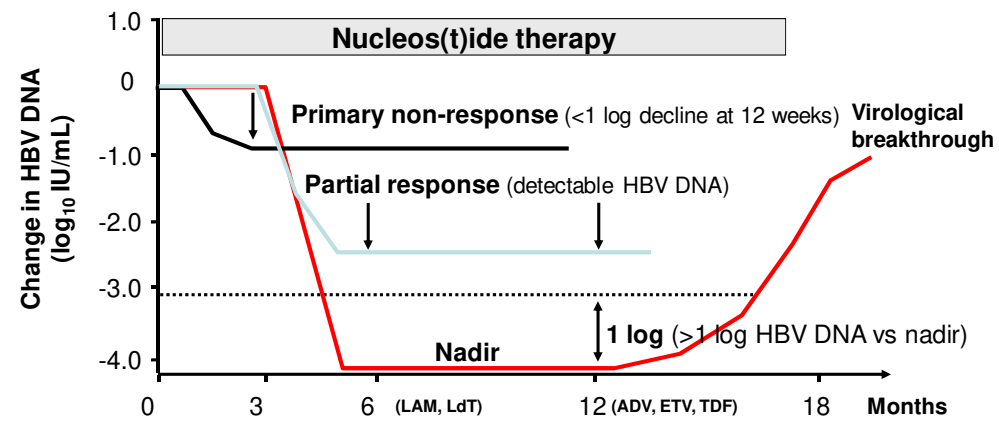

EASL 2012 HBV Guidelines (Ref. 7)

Figure 6. Antiviral treatment failure in patients receiving NA-therapy

Primary non response is defined as less than $1 \log _{10} \mathrm{IU} / \mathrm{ml}$ decrease in HBV DNA level from baseline after 3 months of therapy; the cause might be attributed to lack of compliance or to reduced drug susceptibility in a particular individual. Primary non response seems to be more frequent with Adefovir than with other NAs because of sub-optimal antiviral efficacy. When a primary non response is identified antiviral treatment should be modified to prevent disease progression and drug resistant development. In a compliant patient HBV genotyping for the identification of possible resistant mutations should be performed and a switch to a more potent NA is recommended [7]. 
Partial virological response is defined as a decrease in HBV DNA of more than $1 \log _{10} \mathrm{IU} / \mathrm{ml}$, but detectable HBV DNA after 24 weeks of therapy in compliant patients treated with low genetic barrier NAs (LAM, LdT) and after 48 weeks in patients receiving ADV.

Several studies demonstrated that in patients with persisting viremia after 24 weeks of LAM therapy or 48 weeks of ADV therapy, there is a greater risk of resistance development with further treatment, compared to patients with undetectable HBV DNA. Therefore, an alternative treatment should be considered in these patients before emergence of genotypic resistance and a change to a more potent drug (entecavir or tenofovir) without cross-resistance is recommended [7]. With the more potent and high genetic barrier drugs, such as ETV and TDF, it has been shown that the rate of viral suppression continues to increase even after one year of treatment, without evidence of drug-resistance [7]. These data suggest that a modification of therapy is not necessary in patients with partial virological response under entecavir or tenofovir, especially in those with declining serum HBV DNA levels. However, in patients with persisting low viremia or when HBV DNA levels do not continue to decline, treatment should be adapted (switching or adding the other drug) in order to maximize viral suppression and prevent long-term resistance [7].

Virological breakthrough is defined as a confirmed increase in HBV DNA level of more than $1 \log _{10} \mathrm{IU} / \mathrm{ml}$ compared to the lowest value (nadir) achieved during treatment. In all patients with a virological breakthrough, treatment compliance should be assessed. In compliant patients, virological breakthrough is related to the selection of HBV drug-resistant mutants [50].

\section{Antiviral drug-resistance}

Antiviral drug-resistance is defined as the reduced susceptibility of a virus to the inhibitory effect of a drug due to adaptive mutations selected under the selective pressure of antiviral therapy. In $\mathrm{CHB}$ patients treated with NAs, antiviral drug-resistance is due to mutations within the Polymerase gene of $\mathrm{HBV}$, thus resulting in amino acid substitutions within the polymerase/ reverse transcriptase, target of all NAs. These amino acid changes reduce the affinity of the enzyme for the antiviral drug, in favor of natural substrates. Moreover, the resistanceassociated mutations selected by a particular NA confer at least some degree of cross-resistance to other members of its structural group but may also diminish the sensitivity to NAs from a different chemical group, thus limiting future treatment options (Figure 7).

Development of antiviral drug-resistance is a complex and multistep phenomenon. Figure 8 shows the chronology of events.

Initially, during antiviral therapy, there is the emergence of mutants containing the primary mutations which are known to confer resistance to the antiviral drug (genotypic resistance). If treatment is continued, resistant mutants are selected under the selective pressure of the drug, and over time become the dominant viral species, producing the progressive increase in serum HBV DNA levels. The virological breakthrough is then followed by a biochemical 
breakthrough, defined as elevation in serum alanine aminotransferase, after achieving normalization. The time span between virological and biochemical breakthrough may vary from weeks to years.

\begin{tabular}{|l|l|l|l|l|l|}
\hline HBV variant & LVD & LdT & ETV & ADV & TDF \\
\hline Wild-type & S & S & S & S & S \\
\hline M204I/V & R & R & I & S & S \\
\hline L180M+M204V & R & R & I & S & S \\
\hline A181T/V & R & R & S & R & I \\
\hline N236T & S & S & S & R & I \\
\hline A181T/V + N236T & R & R & S & R & R \\
\hline L180M+M204V/I $\pm I 169 T \pm T 184 G \pm$ & R & R & R & S & S \\
S202I/G $\pm M 250 I / V$ & & & & & \\
\hline
\end{tabular}

$\mathbf{S}=$ sensitive, I= intermediate/reduced susceptibility, $\mathbf{R}=$ resistant

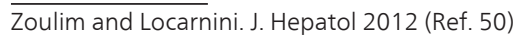

Figure 7. Cross-resistance data for the most frequent resistant HBV variants

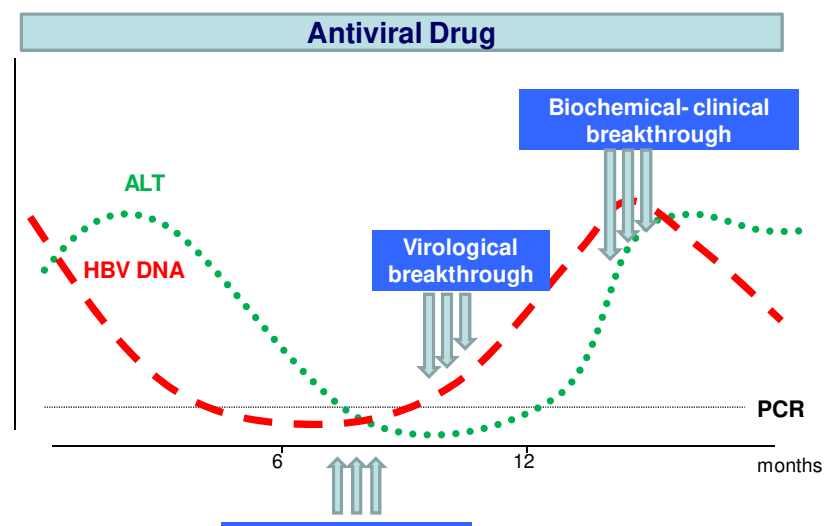

Genotypic resistance

Figure 8. Chronology of events in patients developing antiviral drug-resistance

Development of antiviral drug-resistance has important clinical implications, as it provokes the loss of clinical benefits due to treatment. The selection of drug-resistant mutants was one of the most important concerns with the first and second generation NAs, especially with LAM (Figure 3). Currently, the availability of most potent antivirals with a high barrier to resistance, such as entecavir and tenofovir, significantly reduced the rates of resistance. Consequently, the correct choice of a first-line monotherapy provides the best chance of preventing treatment failure and drug resistance. 
In clinical practice, the early identification of the virologic breakthrough permits an effective timely rescue therapy, before the biochemical breakthrough, thus avoiding disease progression, decompensation in patients with advanced cirrhosis, and accumulation of secondary mutations which may improve viral fitness and may become the basis for cross-resistance with other NAs.

In all patients with a virological breakthrough, genotypic resistance testing should be performed to confirm genotypic resistance and to determine the pattern of mutations. There are two commercially available methods for detection of resistance mutations: a direct PCR-based sequencing, which detects all mutations present in a resistant mutant if it is present in $\geq 20 \%$ of the viral quasispecies, and a hybridization-based genotyping method, which can detect only known nucleotide mutations, but is more sensitive, allowing for detection of mutants when they constitute $5 \%$ or more of the total viral population.

The management of treatment failure has changed significantly in recent years, due to the availability of potent antivirals. An appropriate rescue therapy should be initiated with the most effective antiviral drug without cross-resistance to reduce the risk of selecting multiple drug-resistant viral strains. The add-on strategy is the therapeutic approach recommended by guidelines, in order to prevent the emergence of multi-drug resistant strains and raise the resistance barrier. However, with the availability of more potent drugs, such as entecavir and tenofovir, there is a trend to recommend a switch to a complementary drug having a high barrier to resistance. Both options are considered in the recent EASL guidelines [7]. Recommendations for treatment adaptation in CHB-resistant patients are showed in Table 3. The switch strategy does not apply to patients who have been exposed to multiple monotherapies; these patients should be treated with add-on strategies in order to minimize the risk of subsequent treatment failure.

\begin{tabular}{|c|c|}
\hline Resistance & Action \\
\hline LAM resistance & Switch to TDF (add ADV if TDF not available) \\
\hline ADV resistance & $\begin{array}{l}\text { If patient was NA naive before ADV: Switch to ETV or TDF; } \\
\text { ETV may be preferred in such patients with high viraemia } \\
\text { If patient had prior LAM resistance: Switch to TDF and } \\
\text { add a nucleoside analogue }\end{array}$ \\
\hline LdT resistance & Switch to or add TDF (add ADV if TDF not available) \\
\hline ETV resistance & Switch to or add TDF (add ADV if TDF not available) \\
\hline TDF resistanc & $\begin{array}{l}\text { TDF resistance not detected to date: add a nucleoside } \\
\text { analogue }\end{array}$ \\
\hline
\end{tabular}




\section{Summary and conclusions}

Chronic hepatitis B remains a serious clinical problem because of its worldwide distribution and potential progression of liver damage. Over the last decades, treatment of $\mathrm{CHB}$ has greatly advanced due to the availability of safe and effective drugs and guidelines have been developed. Both Peg-IFN and two NAs, entecavir and tenofovir, can currently be indicated as firstline therapies for $\mathrm{CHB}$.

Peg-IFN treatment is a short-term treatment strategy which provides a significant offtreatment sustained responses, including loss of HBsAg. However, as Peg-IFN is effective in $20-30 \%$ of patients, it should, therefore, be considered only for patients with an elevated possibility of response based on pre-treatment and on-treatment factors. In particular quantitative HBV-DNA and HBsAg may be suitable to early identify patients who are unlikely to benefit from Peg-IFN early during the treatment course, thereby avoiding unnecessary treatment. Nevertheless, despite this individualised and response-guided approach, increasing the cost-effectiveness of Peg-IFN therapy remains a clinical challenge. Combining Peg-IFN with NA appears to be the most appealing approach to increase the efficacy of antiviral therapy and new trials on a combination of Peg-IFN with ETV or TDF are required.

Currently, nucleos(t)ides analogues represent the treatment option used in the majority of $\mathrm{CHB}$ patients due to their potent antiviral effect, oral administration (one oral tablet daily) and optimum tolerance. In registration trials, entecavir and tenofovir, third-generation potent antivirals with a high barrier to resistance, showed long-term HBV-DNA suppression, low rise of resistance, potential reversion of fibrosis and no progression to cirrhosis, and lower risk of adverse clinical events in cirrhotic patients, except for HCC development. Real life studies have confirmed the long-term efficacy and safety of these two first-line NAs. However, NAs require a long-term, perhaps indefinite, treatment thus raising several concerns: patient's commitment to lifelong treatment, adherence, longterm safety, drug resistance in the long-term and costs. Combination of IFN and NAs might achieve an antiviral synergy and provide new opportunities to increase HBsAg clearance rates and shorten treatment duration. New studies exploring different strategies of combining Peg-IFN with ETV or TDF are required to further improve the treatment of chronic hepatitis $B$.

\section{Author details}

Teresa Santantonio* and Massimo Fasano

*Address all correspondence to: t.santantonio@unifg.it

Department of Clinical and Experimental Medicine, University of Foggia, Foggia, Italy 


\section{References}

[1] Lavanchy, D. Hepatitis B virus epidemiology, disease burden, treatment, and current and emerging prevention and control measures. J Viral Hepat (2004). , 11, 97-107.

[2] Fattovich, G. Natural history and prognosis of hepatitis B. Semin Liver Dis (2003). , 23, 47-58.

[3] Hui, C. K, Leung, N, Yuen, S. T, Zhang, H. Y, Leung, K. W, Lu, L, et al. Natural History and Disease Progression in Chinese Chronic Hepatitis B Patients in Immune-tolerant Phase. Hepatology (2007). , 46, 395-401.

[4] Brunetto, M. R, Oliveri, F, Colombatto, P, Moriconi, F, Ciccorossi, P, Coco, B, et al. Hepatitis B surface antigen serum levels help to distinguish active from inactive hepatitis B virus genotype D carriers. Gastroenterology (2010). , 139, 483-490.

[5] Raimondo, G, Allain, J. P, Brunetto, M. R, Buendia, M. A, Chen, D. S, Colombo, M, et al. Statements from the Taormina expert meeting on occult hepatitis B virus infection. J Hepatol (2008). , 49, 652-657.

[6] Zerbini, A, Pilli, M, Boni, C, Fisicaro, P, Penna, A, Di Vincenzo, P, et al. The characteristics of the cell-mediated immune response identify different profiles of occult hepatitis B virus infection. Gastroenterology (2008). , 134, 1470-1481.

[7] European Association for the Study of the Liver. EASL Clinical Practice Guidelines: Management of chronic hepatitis B virus infection. J Hepatol (2012). , 57, 167-185.

[8] Lok, A. S, \& McMahon, B. J. Chronic hepatitis B: Update 2009. Hepatology (2009). , 50, 661-662.

[9] Liaw, Y. F, Leung, N, Kao, J. H, Piratvisuth, T, Gane, E, Han, K. H, et al. Asian-Pacific consensus statement on the management of chronic hepatitis B: a 2008 update. Hepatol Int (2008). , 2, 263-283.

[10] Castera, L. Non invasive methods to assess liver disease in patients with hepatitis B or C. Gastroenterology (2012). , 142, 1293-1302.

[11] Fattovich, G, Bortolotti, F, \& Donato, F. Natural history of chronic hepatitis B: special emphasis on disease progression and prognostic factors. J Hepatol (2008). , 48, 335-352.

[12] Yang, H. I, Lu, S. N, Liaw, Y. F, You, S. L, Sun, C. A, Wang, L. Y, et al. Hepatitis B e antigen and the risk of hepatocellular carcinoma. N Engl J Med (2002). , 347, 168-174.

[13] Iloeje, U. H, Yang, H. I, Su, J, Jen, C. L, You, S. L, Chen, S. J, et al. Predicting cirrhosis risk based on the level of circulating hepatitis B viral load. Gastroenterology (2006). , $130,678-686$.

[14] Chen, C. J, Yang, H. I, Su, J, Jen, C. L, You, S. L, Lu, S. N, et al. Risk of hepatocellular carcinoma across a biological gradient of serum hepatitis B virus DNA level. JAMA (2006). , 295, 65-73. 
[15] Van Zonneveld, M, Flink, H. J, Verhey, E, Senturk, H, Zeuzem, S, Akarca, U. S, et al. The safety of pegylated interferon alpha- $2 b$ in the treatment of chronic hepatitis B: predictive factors for dose reduction and treatment discontinuation. Aliment Pharmacol Ther (2005). , 21, 1163-1171.

[16] Lau, G. K, Piratvisuth, T, Luo, K. X, Marcellin, P, Thongsawat, S, Cooksley, G, et al. Peginterferon alpha-2a, Lamivudine, and the combination for HBeAg-positive chronic hepatitis B. N Engl J Med (2005). , 352, 2682-2695.

[17] Lau, G. K, Piratvisuth, T, Luo, H. X, Marcellin, P, Thongsawat, S, Cooksley, G, et al. Durabilty of response and occurrence of late response to peginterferon alpha-2a (40KD) [Pegasys] one year post-treatment in patients with HBeAg-posive chronic hepatitis B. J Hepatol (2006). Abs 50.

[18] Buster, E. H, Flink, H. J, Cakaloglu, Y, Simon, K, Trojan, J, Tabak, F, et al. Sustained HBeAg and HBsAg loss after long-term follow-up of HBeAg positive patients treated with peginterferon alpha-2b. Gastroenterology (2008). , 135, 459-467.

[19] Buster EHCJ, Hansen BE, Lau GK, Piratvisuth T, Zeuzem S, Steyerberg EW, et al. Factors that predict response of patients with hepatitis B e antigen-positive chronic hepatitis B to peginterferon-alfa. Gastroenterology (2009). , 137, 2002-2009.

[20] Piratvisuth, T, et al. Sustained Immune Control 1 Year Post-Treatment With Peginterferon Alfa-2a [40KD] (PEGASYS) is Durable up to 5 Years Post-Treatment and is Associated With a High Rate of HBsAg Clearance in HBeAg-Negative Chronic Hepatitis B. Hepatol Int (2010). Abs210.

[21] Marcellin, P, Lau, G. K, Bonino, F, et al. Peginterferon alfa-2a alone, lamivudine alone, and the two in combination in patients with HBeAg-negative chronic hepatitis B. N Engl J Med (2004). , 351, 1206-1217.

[22] Piccolo, P, Lenci, I, Demelia, L, Bandiera, F, Piras, M. R, Antonucci, G, et al. A randomized controlled trial of pegylated interferon-alpha2a plus adefovir dipivoxil for hepatitis B e antigen-negative chronic hepatitis B. Antivir Ther (2009). , 14, 1165-1174.

[23] Rijckborst V, ter Borg MJ, Cakaloglu Y, Ferenci P, Tabak F, Akdogan M, et al. A randomized trial of peginterferon alpha-2a with or without ribavirin for HBeAgnegative chronic hepatitis B. Am J Gastroenterol. (2010). , 105, 1762-1769.

[24] Liaw, Y. F, Jia, J. D, Chan, H. L, Han, K. H, Tanwandee, T, Chuang, W. L, et al. Shorter durations and lower doses of peginterferon alfa-2a are associated with inferior hepatitis B e antigen seroconversion rates in hepatitis B virus genotypes B or C. Hepatology. (2011). , 54, 1591-1599.

[25] Lampertico P, Viganò M, Di Costanzo GG, Sagnelli E, Fasano M, Di Marco V, et al. Randomised study comparison 48 and 96 weeks peginterferon $\alpha$-2a therapy in genotype D HBeAg-negative chronic hepatitis B. Gut (2012). Epub ahead of print] 
[26] Janssen HLA, van Zonneveld M, Senturk H, Zeuzem S, Akarca US, Cakaloglu Y, et al. Pegylated interferon alfa- $2 \mathrm{~b}$ alone or in combination with lamivudine for HBeAgpositive chronic hepatitis B: a randomized trial. Lancet (2005). , 365, 123-129.

[27] Sonneveld, M. J, Rijckborst, V, Zeuzem, S, Heathcote, E. J, Simon, K, Senturk, H, Pas, S. D, Hansen, B. E, \& Janssen, H. Presence of precore and core promoter mutants limits the probability of response to peginterferon in hepatitis $\mathrm{B}$ e antigen-positive chronic hepatitis B. Hepatology (2012). , 56, 67-74.

[28] Tseng, T. C, Yu, M. L, Liu, C. J, Lin, C. L, Huang, Y. W, Hsu, C. S, et al. Effect of host and viral factors on hepatitis $B$ e antigen-positive chronic hepatitis $B$ patients receiving pegylated interferon alpha-2a therapy. Antivir Ther (2011). , 16, 629-637.

[29] Sonneveld, M. J, Wong, V. W, Woltman, A. M, Wong, G. L, Cakaloglu, Y, Zeuzem, S, et al. Polymorphisms near IL28B and serological response to peginterferon in HBeAgpositive patients with chronic hepatitis B. Gastroenterology (2012). , 142, 513-520.

[30] Wu, X, Xin, Z, Zhu, X, Pan, L, Li, Z, Li, H, et al. Evaluation of susceptibility locus for response to interferon-alpha based therapy in chronic hepatitis B patients in Chinese. Antiviral Res (2012). , 93, 297-300.

[31] Lampertico, P, Viganò, M, Cheroni, C, Facchetti, F, Invernizzi, F, Valveri, V, et al. IL28B polymorphisms predict interferon-related HBsAg seroclearance in genotype D HBeAgnegative patients with chronic hepatitis B. Hepatology (2012). Epub ahead of print]

[32] Sonneveld, M. J, Rijckborst, V, Boucher, C. A, Hansen, B. E, \& Janssen, H. L. Prediction of sustained response to peginterferon alpha- $2 \mathrm{~b}$ for hepatitis $\mathrm{B}$ e antigen-positive chronic hepatitis B using on-treatment hepatitis B surface antigen decline. Hepatology (2010). , 52, 1251-1257.

[33] Piratvisuth, T, Marcellin, P, Popescu, M, Kapprell, H. P, Rothe, V, \& Lu, Z. M. Hepatitis $B$ surface antigen: association with sustained response to peginterferon alfa-2a in hepatitis B e antigen-positive patients. Hepatol Int (2011). Epub ahead of print]

[34] Rijckborst, V, Hansen, B. E, Cakaloglu, Y, Ferenci, P, Tabak, F, Akdogan, M, et al. Early on-treatment prediction of response to peginterferon alpha-2a for HBeAg-negative chronic hepatitis B using HBsAg and HBV DNA levels. Hepatology (2010). , 52, 454-461.

[35] Rijckborst, V, Hansen, B. E, Ferenci, P, Brunetto, M. R, Tabak, F, Cakaloglu, Y, et al. Validation of a stopping rule at week 12 using HBsAg and HBV DNA for HBeAgnegative patients treated with peginterferon alfa-2a. J Hepatol (2012). , 56, 1006-1011.

[36] Chang TT, Lai CL, Kew Yoon S, Lee SS, Coelho HS, Carrilho FJ, et al. Entecavir treatment for up to 5 years in patients with hepatitis B e antigen-positive chronic hepatitis B. Hepatology (2010). , 51, 422-430.

[37] Shouval, D, Lai, C. L, Chang, T. T, Gadano, A, Wu, S. S, Halota, W, et al. Three years of entecavir (ETV) re-treatment of $\mathrm{HBeAg}(-)$ ETV patients who previously discontinued ETV treatment: results from study ETV-901. Hepatology (2008). Abs 927. 
[38] Marcellin, P, Heathcote, E. J, Buti, M, Gane, E, De Man, R. A, Krastev, Z, et al. Tenofovir disoproxil fumarate versus adefovir dipivoxil for chronic hepatitis B. N Engl J Med. (2008). , 359, 2442-2455.

[39] Heathcote, E. J, Marcellin, P, Buti, M, Gane, E, De Man, R. A, Krastev, Z, et al. Threeyear efficacy and safety of tenofovir disoproxil fumarate treatment for chronic hepatitis B. Gastroenterology (2011). , 140, 132-43.

[40] Marcellin, P, Buti, M, Gane, E. J, Krastev, Z, Flisiak, R, Germanidis, G, et al. Five years of treatment with tenofovir DF (TDF) for chronic hepatitis B (CHB) infection is associated with sustained viral suppression and significant regression of histological fibrosis and cirrhosis. Hepatology (2011). Suppl 1):1011A-1012A. Abs 1375.

[41] Tenney, D. J, Rose, R. E, Baldick, C. J, Pokornowski, K. A, Eggers, B. J, Fang, J, et al. Long-term monitoring shows hepatitis $B$ virus resistance to entecavir in nucleosidenaive patients is rare through 5 years of therapy. Hepatology (2009). , 49, 1503-1514.

[42] Snow-lampart, A, Chappell, B, Curtis, M, Zhu, Y, Myrick, F, Schawalder, J, et al. No resistance to tenofovir disoproxil fumarate detected after up to 144 weeks of therapy in patients monoinfected with chronic hepatitis B virus. Hepatology (2011). , 53, 763-773.

[43] Manns, M, Akarca, U. S, Chang, T. T, Sievert, W, Yoon, S-K, Tsai, N, et al. Low rates of nucleos(t)ide-associated adverse events in the long-term experience with entecavir. J Hepatol (2010). S393. Abs 1016.

[44] Lampertico, P, Soffredini, R, Invernizzi, F, Vigano, M, Facchetti, F, Minola, E, et al. Maintained viral suppression and excellent safety profile of Entecavir monotherapy in 418 NUC-naïve patients with chronic hepatitis B: a 4-year field practice, multicenter study. J Hepatol (2012). S206. Abs 522.

[45] Seto WK, Lai CL, Fung J, Yuen DKH, Wong M, Yuen MF. Outcome of 4-year treatment of entecavir for treatment-naive chronic hepatitis B. J Hepatol (2011). S301. Abs 748.

[46] Buti, M, Morillas, R. M, Prieto, M, Diago, M, Pérez, J, Solà, R, et al. Efficacy and safety of entecavir in clinical practice in treatment-naive Caucasian chronic hepatitis $\mathrm{B}$ patients. Eur J Gastroenterol Hepatol (2012). , 24, 535-542.

[47] Zoutendjik, R, Reijnders, J. G, Brown, A, et al. Entecavir treatment for chronic hepatitis $\mathrm{B}$ : adaptation is not needed for the majority of naïve patients with a partial virologic response. Hepatology (2011). , 54, 443-451.

[48] Zoutendijk, R, Reijnders, J, Zoulim, F, Brown, B, Mutimer, D, Deterding, K, et al. Virological response to Entecavir is associated with a better clinical outcome in chronic hepatitis B patients. Gut (2012). Epub ahead of print]

[49] Lampertico, P, Soffredini, R, Vigano, M, Yurdaydin, C, Idilman, R, Papatheodoridis, G. V, et al. Tenofovir monotherapy for naïve patients with chronic hepatitis B: a 
multicenter European study in clinical practice in 302 patients followed for 30 months. J Hepatol (2012). S208. Abs 525.

[50] Zoulim, F, \& Locarnini, S. Management of treatment failure in chronic hepatitis B. J Hepatol (2012). Suppl 1:S, 112-122. 